\title{
Ileal meconium plugs
}

\author{
VASANT C TALWALKER AND DINESH H KITTUR \\ Department of Paediatric Surgery, Grant Medical College, Bombay, India
}

SUMMARY Eleven cases of neonatal intestinal obstruction associated with a white ileal meconium plug are described; 6 of these presented with complications-such as, giant meconium pseudocyst, perforation, volvulus, or atresia. Most of these complications are presumed to have arisen during the intrauterine period. Only one patient could be relieved of the ileal meconium plug by enemas. The condition of ileal meconium plug is not as benign as a meconium plug in the rectum or distal colon. A plea is made to restrict the name meconium plug syndrome to cases in which the meconium plug is white and chalky and the consequent intestinal obstruction can be relieved by enemas, without evidence of intestinal dysfunction in later life.

In the classical description of the meconium plug syndrome, ${ }^{1}$ a newly born infant fails to pass meconium, and so develops intestinal obstruction. After a rectal digital examination or an enema, the obstruction is relieved by the passage of a greyish white meconium plug. These infants do not have underlying problems of intestinal dysfunction as in Hirschsprung's disease or cystic fibrosis. The prognosis is reported to be good. In this paper 11 patients are described; each had a greyish-white meconium plug in the terminal ileum in contradistinction to obturation of the distal large bowel. This meconium plug was similar to that described by Clatworthy $e t$ al. who reported 2 cases with obstruction in the terminal ileum. ${ }^{1-2}$

\section{Patients and methods}

Between 1966 and 1978 about 200 cases of neonatal intestinal obstruction were seen. In 11 of these the lesion included an ileal meconium plug. These patients were being treated in various hospitals in Bombay -6 at the J J Hospital. The cases have been studied retrospectively and analysed.

\section{Observations}

All the 11 patients presented with low intestinal obstruction (Table). There were 8 boys and 3 girls. Most patients presented within 4 days of birth, while one (Case 2) took 15 days to reach the hospital

Department of Paediatric Surgery, Grant Medical College, Bombay

VASANT C TALWALKER, paediatric surgeon

DINESH H KITTUR, lecturer from a remote area. This child arrived in a marasmic condition, but surprisingly was still alive, despite having had complete obstruction since birth. Except for one patient, none had passed meconium. In the one exception (Case 5), white plugs of meconium were passed after rectal examination without relief of obstruction. This patient was relieved by repeated enemas using glycerine. Two patients (Cases 1 and 3) had each had a sibling who had died of a similar illness.

All the patients had abdominal distension, two had palpable abdominal masses (Cases 6 and 8). Two patients had $x$-ray evidence of gas under the diaphragm, indicating a perforation (Cases 3 and 7). Four of these patients (Cases 1, 4, 5, and 9) had straightforward intestinal obstructions due to the meconium plug. The other 7 patients had additional lesions. Two of them had perforations with meconium peritonitis (Cases 3 and 7). One had a giant meconium pseudocyst (Case 6) suggesting an antenatal perforation. One presented with a volvulus of dilated loops of ileum (Case 8). Two patients (Cases 2 and 11) had atresias of the ileum and jejunum proximal to a long length of white meconium plug in the ileum. Aganglionosis was a contributing factor in two patients (Cases 7 and 10).

\section{Discussion}

Clatworthy and his colleagues reviewed 30 reported cases which had been seen at one hospital. ${ }^{2}$ Only 2 of their patients had meconium plugs in the terminal ileum. In the remainder, the meconium plug was in the colon. In spite of their excellent description, ${ }^{1}$ there have been few further reports of the meconium 
Table Details of 11 cases

\begin{tabular}{|c|c|c|c|c|c|}
\hline Case & Age (hours) & $\operatorname{Sex}$ & Findings (operative or otherwise) & Procedure & Result \\
\hline 1 & 96 & $\mathbf{F}$ & $\begin{array}{l}\text { White meconium plug in terminal loop of ileum }(15 \mathrm{~cm}) \\
\text { Normal looking meconium in proximal dilated ileum }\end{array}$ & Ileostomy & Died \\
\hline 2 & 15 days & $\mathbf{M}$ & $\begin{array}{l}\text { Whole of ileum filled with meconium plugs. Atresia of jejunum } \\
20 \mathrm{~cm} \text { from D J flexure. Microcolon }\end{array}$ & $\begin{array}{l}\text { Resection of atretic part of } \\
\text { jejunum and anastomosis after } \\
\text { milking out the meconium } \\
\text { plugs }\end{array}$ & Died \\
\hline 3 & 10 & $\mathbf{M}$ & $\begin{array}{l}\text { Meconium and air in the peritoneal cavity and scrotal sac. } \\
\text { Perforations in ileum at } 7 \mathrm{~cm} \text {, and } 16 \mathrm{~cm} \text { from the } \\
\text { ileocaecal junction. White meconium plug in terminal } 6 \mathrm{~cm} \\
\text { of ileum. Gangrene of ileum }\end{array}$ & Excision and ileostomy & Died \\
\hline 4 & 24 & $\mathbf{F}$ & Meconium plug at ileocaecal junction. 'Spasm' of colon & Resection and anastomosis & Died \\
\hline 5 & 48 & $\mathbf{M}$ & $\begin{array}{l}\text { Low intestinal obstruction. Contrast enema showed } \\
\text { microcolon and meconium plugs in terminal ileum (Fig. 1) }\end{array}$ & $\begin{array}{l}\text { Repeated enemas using } \\
\text { glycerine }\end{array}$ & $\begin{array}{l}\text { Obstruction } \\
\text { relieved }\end{array}$ \\
\hline 6 & 12 & $\mathbf{M}$ & $\begin{array}{l}\text { Giant meconium pseudocyst. Perforation in ileum } 15 \mathrm{~cm} \text { from } \\
\text { ileocaecal junction. Meconium plugs in terminal ileum }(5 \mathrm{~cm})\end{array}$ & Ileostomy & Died \\
\hline 7 & 48 & $\mathbf{M}$ & $\begin{array}{l}\text { Meconium peritonitis. Perforation in ileum } 20 \mathrm{~cm} \text { from } \\
\text { ileocaecal junction. White meconium plug in last } 8 \mathrm{~cm} \text { of } \\
\text { ileum }\end{array}$ & Resection and anastomosis & Died \\
\hline 8 & 48 & $\mathbf{F}$ & $\begin{array}{l}\text { Mass in right iliac fossa due to volvulus of dilated ileum. } \\
\text { White plug of meconium in last loop of ileum for } 7 \mathrm{~cm}\end{array}$ & Resection and anastomosis & Living \\
\hline 9 & 48 & $\mathbf{M}$ & $\begin{array}{l}\text { Intestinal obstruction at ileocaecal junction due to white } \\
\text { meconium plug in terminal ileum. Baby later developed } \\
\text { burst abdomen and perforation of ileum }\end{array}$ & $\begin{array}{l}\text { Resection and anastomosis. } \\
\text { Resuturing of abdomen after } \\
\text { closure of perforation }\end{array}$ & $\begin{array}{c}\text { Died at } 6 \\
\text { weeks }\end{array}$ \\
\hline 10 & 96 & $\mathbf{M}$ & $\begin{array}{l}\text { Obstruction in ileum, } 40 \mathrm{~cm} \text { away from caecum. } \\
\text { Terminal ileum filled with white meconium. Proximal } \\
\text { ileum filled with dark meconium }\end{array}$ & $\begin{array}{l}\text { Resection of terminal and } \\
\text { proximal half transverse colon }\end{array}$ & Died \\
\hline 11 & 36 & $\mathbf{M}$ & $\begin{array}{l}\text { Ileal atresia about } 10 \mathrm{~cm} \text { from the ileocaecal junction with a } \\
\text { peritoneal band causing a kinking and near atresia of the } \\
\text { proximal loop about } 5 \mathrm{~cm} \text { away. Both dilated loops } \\
\text { contained green meconium. Distal ileal loops as well as } \\
\text { caecum and proximal half of transverse colon contained } \\
\text { white meconium. The distal colon was unused. Microcolon }\end{array}$ & $\begin{array}{l}\text { Resection and ileoileal } \\
\text { anastomosis }\end{array}$ & $\begin{array}{l}\text { Died after } \\
48 \text { hours }\end{array}$ \\
\hline
\end{tabular}

plug syndrome during the last 20 years. ${ }^{3-5}$ Perhaps the classical meconium plug syndrome has been so well described that it is no longer reported. However, obstruction due to a meconium plug at the terminal ileum appears to be rare. None of our 200 patients with neonatal intestinal obstruction suffered from meconium ileus due to cystic fibrosis. It appears that meconium ileus is rare even in Bombay where meconium plugs are more common but, surprisingly, there was not a single case of rectal meconium plug in our series. It is possible that in some the obstruction was relieved by a glycerine enema without the patient being referred to a surgeon. In contrast, just over 50 cases of neonatal Hirschsprung's disease were seen during the same period.

Six out of the 11 patients presented with what

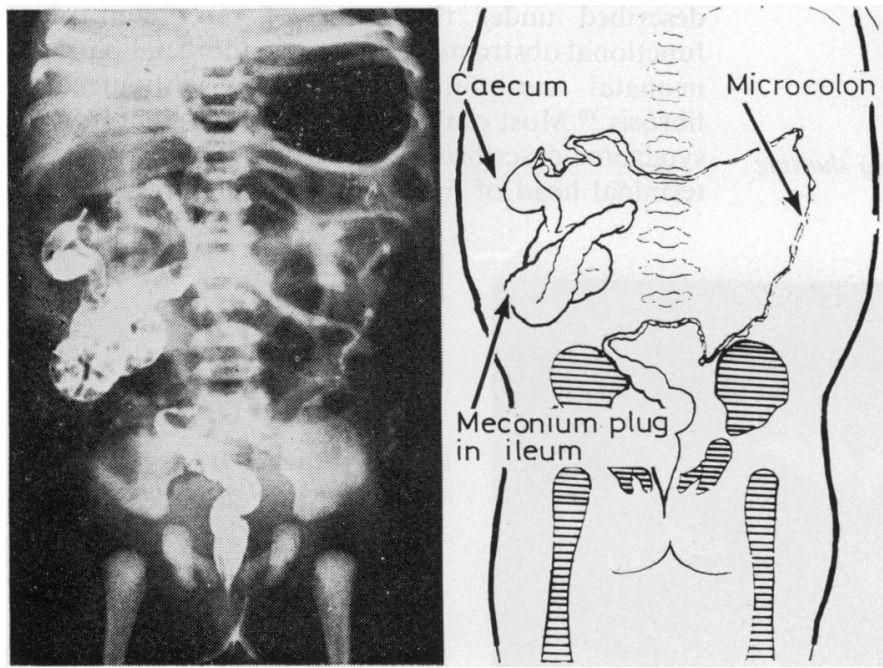

Fig. 1 (Case 5). Contrast enema showing microcolon and the caecum and the ileal loops filled with meconium plug. 
appeared to be an ileal plug alone. The other 5 patients presented with a more striking complication. It seems likely that complications-namely, perforation, pseudocyst formation, volvulus, and perhaps even the jejunal and ileal atresia-were secondary to the obstruction caused by an ileal meconium plug. Although complications such as perforation have been reported in association with Hirschsprung's disease, ${ }^{6}$ they have not previously been described in association with meconium plugs. If there is evidence

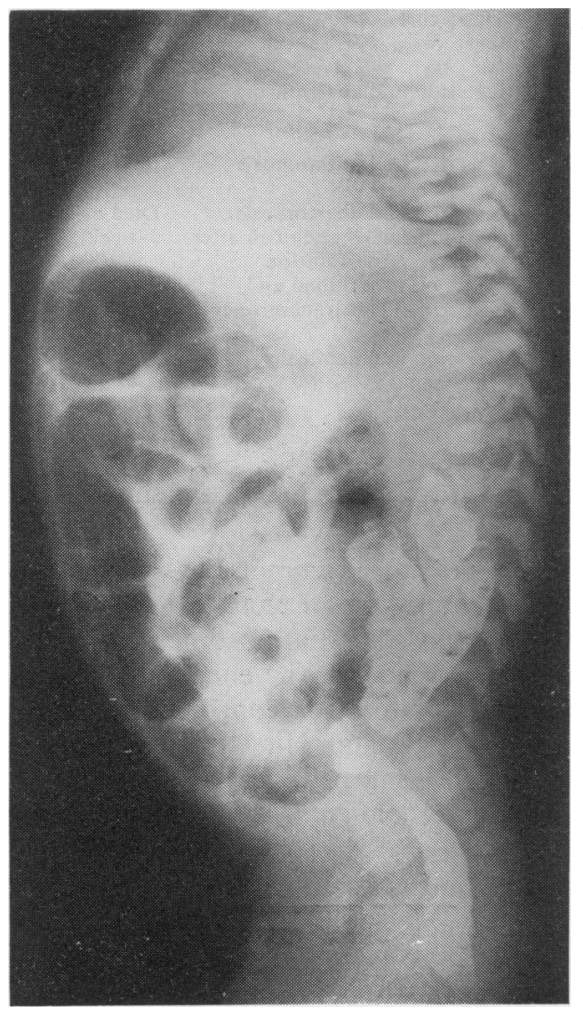

Fig. 2 (Case 5). Lateral view of contrast enema showing ileal loops filled with meconium plug. of neonatal perforation or volvulus, it is a good practice to look for an underlying cause, such as Hirschsprung's disease or, in our experience, a meconium plug in the terminal ileum. It must be stressed that presence of a meconium plug in the ileum does not exclude the possibility of Hirschsprung's disease. This was classically present in one case (Case 7), and in another patient (Case 10), histology showed aganglionosis of the entire bowel. ${ }^{7}$ This association of meconium plugs and Hirschsprung's disease has been noted by other authors. ${ }^{25}$

The apparent concentration of ileal meconium plugs in Bombay suggests a genetic element in the aetiology. Two of our 11 patients gave a history of a previous sibling dying of 'similar illness', but we do not have any further information. On the other hand, the 11 patients reported belonged to various endogamous communities in the local population.

One patient in our series (Case 5) had an ileal meconium plug which was demonstrated by a radio-opaque enema (Figs 1 and 2). This was relieved by repeated glycerine enemas administered with a syringe (Fig. 3). This seems to be the only recorded instance of an ileal meconium plug obstruction being relieved without open operation. Only one of the other 10 patients (Case 8) has survived. These two survivors have not subsequently had any intestinal dysfunction. We have experienced a high mortality with ileal meconium plugs, mainly because of the high incidence of complications. Ileal meconium plugs are not always benign and it seems that there can be serious complications in intrauterine life.

Intestinal obstruction in the newborn due to abnormalities of meconium may be due to various causes. Apart from meconium ileus due to cystic fibrosis, several types of obstruction have been described under the name of meconium plug, ${ }^{3}$ functional obstruction, ${ }^{8}$ terminal anorectal plugs, ${ }^{9}$ or neonatal meconium obstruction without cystic fibrosis. ${ }^{10}$ Most of these cases were different from the syndrome described by Clatworthy et al. ${ }^{1}$ where the terminal head of meconium is white and chalky. It

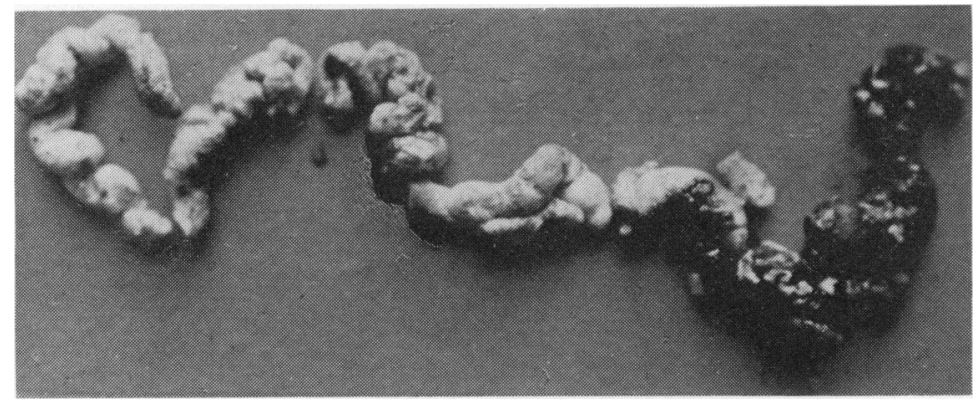

Fig. 3 (Case 5). White plug with adjoining normal meconium. 
seems to us that the term 'meconium plug', should be reserved for those white meconium plugs in which the terminal head of meconium does not contain any green bile pigments. The term meconium plug syndrome should be used only to describe the obstruction caused by such a plug, if it can be relieved by enemas. The fact that these children do not have any other bowel problems in later life suggests that the causation of the meconium plug syndrome is related to a delay in the delivery of the hepatic secretions into the gastrointestinal tract in intrauterine life.

\section{References}

1 Clatworthy H W Jr, Howard W H R, Lloyd J. The meconium plug syndrome. Surgery 1956; 39 : 131-42.

2 Ellis D G, Clatworthy H W, Jr. The meconium plug syndrome revisited. J Pediatr Surg 1966; 1: 54-61.

3 Zachary R B. Meconium and faecal plugs in the newborn. Arch Dis Child 1957; 32: 22-4.
- Swischuk L E. Meconium plug syndrome. A cause of neonatal intestinal obstruction. AJR 1968; 103: 339-46.

5 Van Leeuween G, Riley W C, Glenn B A, Woodruff G. Meconium plug syndrome with aganglionosis. Pediatrics 1967; 40: 665-6.

- Ehrenpreis S T. In: Hirschsprung's disease. Chicago: Year Book Medical Publishers, 1970: 80-2.

7 Talwalker V C. Aganglionosis of entire bowel. J Pediatr Surg 1976; 11: 213-6.

8 Rack F J, Crouch W L. Functional obstruction in the premature infant. J Pediatr 1952; 40: 579-83.

9 Emery J L. Abnormalities in meconium of the foetus and newborn. Arch Dis Child 1957; 32: 17-21.

10 Rickham P P, Boeckman C R. Neonatal meconium obstruction in the absence of mucoviscidosis. Am J Surg 1965; 109: 173-7.

Correspondence to V C Talwalker FRCS, Department of Paediatric Surgery, J J Hospital, Bombay, India.

Received 27 March 1979

The following articles will appear in future issues of this journal:

Toddler's diarrhoea. J A Walker-Smith

Effect of feeding on jugular venous blood flow in the normal newborn infant. $P R F$ Dear

Antiglobulin antibody in the sera of contacts of children with leukaemia. A Wang, M Till, and J F Soothill

Shwachman's syndrome. A review of 21 cases. P J Aggett, N P C Cavanagh, D J Matthew, J R Pincott $J$ Sutcliffe, and $J T$ Harries

Factor X deficiency in the neonatal period. SJ Machin, M R Winter, S C Davies, and IJ Mackie

Hypoxia in a neonate caused by intermittent positive pressure ventilation. I R Beddis and $M$ Silverman 